\title{
Examination of Cultural and Gender Similarities and Differences among Canadian and U.S. College Students on a Measure of Manifest Anxiety
}

\author{
Patricia A. Lowe ${ }^{1}$ \\ ${ }^{1}$ Department of Educational Psychology, University of Kansas, Lawrence, Kansas, USA \\ Correspondence: Patricia A. Lowe, Department of Educational Psychology, University of Kansas, Lawrence, \\ Kansas, USA. Tel: 1-785-864-9710. E-mail: tlowe@ku.edu
}

Received: July 3, $2018 \quad$ Accepted: July 20, $2018 \quad$ Online Published: August 20, 2018

doi:10.5539/hes.v8n3p94 URL: https://doi.org/10.5539/hes.v8n3p94

\begin{abstract}
A measurement invariance study was conducted among 1,344 college students from Canada and the United States on an anxiety measure specifically designed for the college student population to determine whether the construct of anxiety was equivalent across country (Canada, United States) and gender. In addition, country and gender differences were examined on the anxiety measure. The Adult Manifest Anxiety Scale-College Version (AMAS-C) was administered to the college students online. The AMAS-C consists of four anxiety (Physiological Anxiety, Social Concerns/Stress, Test Anxiety, and Worry/Oversensitivity) subscales, a Total Anxiety scale, and a Lie scale. Results of tests of measurement invariance found the construct of anxiety equivalent across country and gender and latent mean analyses found gender differences, but no country differences, on the AMAS-C anxiety factors. Implications of the findings for mental health professionals, educational practitioners, and current and future researchers who work with or who will work with the undergraduate student population in Canada are discussed.
\end{abstract}

Keywords: anxiety, college students, Canada, United States, validity, cultural similarities, cultural differences, gender differences

\section{Introduction}

Anxiety is a universal construct. However, the level and form of expression may vary based on the cultural context (Bodas \& Ollendick, 2005). The Canadian and U.S. cultures are reported to have many similarities, such as similar values (Bassani, 2005; Bowman, 2000) and higher educational systems (Triventi, 2014), but they also have some cultural differences, such as universal health care, immigration policies, and diversity on college campuses (Bowman, 2000). For example, taxes are used to pay for universal health care in Canada and due to universal health care, Canadians are reported to have better physical and mental health than Americans (Bowman, 2000), with lower prevalence of psychiatric disorders reported (Kessler et al., 1997), including anxiety. Another example of cultural differences is that minority status in the United States is more closely tied to income disadvantage than in Canada and income disadvantage is associated with poorer well-being (Bowman, 2000), including higher levels of anxiety (DeCarlo, Wadsworth, \& Stump, 2011). Therefore, some cultural differences do exist in Canada and the United States and it is unclear whether these differences in the two cultures influence any differences in the level and expression of anxiety experienced in college students in these two countries.

Anxiety, depression, and substance use are common problems among Canadian and U.S. college students (American Psychological Association, 2015; Craggs, 2012; Cranford, Eisenberg, \& Serras, 2009; Eisenberg, Gollust, Golberstein, \& Hefner, 2007; Nunes et al., 2014; Zivin, Eisenberg, Gollust, \& Golberstein, Golberstein, 2009), with about $11.9 \%$ of college students reported to have an anxiety disorder (Pedrelli, Nyer, Yeung, Zulauf, \& Wilens, 2015). Anxiety is the most prevalent mental health problem, and it along with other mental health problems are increasing among the college student population (Pedrelli et al., 2015) and are reported to be higher than in the general population (Stallman, 2010). Both Canadian and U.S. college students are reported to be overwhelmed with anxiety (American Psychological Association, 2015; Craggs, 2012; Cranford et al., 2009; Eisenberg et al., 2007; Nunes et al., 2014; Regehr, Glancy, \& Pitts, 2013), with some anxieties being more specific to the college-age student population (e.g., academic pressures, separation and individuation, formation 
of significant adult relationships, and new financial responsibilities, Pedrelli et al., 2015; Tosevski, Milvancevic, \& Gajic, 2010). For those college students who are anxious or stressed, academic struggles and dropout are more likely to occur (Gerwing, Rash, Gerwing, Bramble, \& Landine, 2015; Stelnicki, Nordstokke, \& Saklofske, 2015) and academic and career goals are less likely to be achieved (Stelnicki et al., 2015). With so many college students experiencing anxiety and academic struggles, a measure designed specifically for the college-age student population would be helpful in identifying those students with anxiety, so those individuals could receive appropriate interventions.

\subsection{The Adult Manifest Anxiety Scale for College Students}

The Adult Manifest Anxiety Scale-College Version (AMAS-C; Reynolds, Richmond, \& Lowe, 2003a) was developed specifically for the U.S. college student population (Reynolds, Richmond, \& Lowe, 2003b). The AMAS-C is a measure of manifest anxiety and "manifest anxiety was derived from a trait theory of anxiety" (Reynolds, 1985, p. 409). Manifest anxiety is a measure of drive (J. T. Spence \& K. W. Spence, 1966) and, according to drive theorists, anxiety is the level of excitability (e.g., the intense autonomic responses and self-disparaging thoughts) a person experiences when confronted with unpleasant stimuli (Zeidner, 1998).

The items on the AMAS-C assess common symptoms of anxiety found among individuals across the lifespan, but it also includes items that assess the unique symptoms of anxiety found among the college-age student population (Lowe, 2013; Lowe \& Reynolds, 2005; Reynolds et al., 2003b). Unlike other measures of trait anxiety, such as the Trait scale of the State-Trait Anxiety Inventory (STAI; Spielberger, Gorsuch, \& Lushene, 1977) and the Trait scale of the Endler Multidimensional Anxiety Scale (EMAS; Endler, Edwards, \& Vitelli, 1990), the AMAS-C items were factor analyzed using only the responses of college students to scale the measure. In addition, the AMAS-C norming sample includes only college students (Reynolds et al., 2003b).

Lowe (2013) conducted a study using confirmatory factor analysis (CFA) and validated the AMAS-C five-factor structure. The AMAS-C consists of four anxiety (Physiological Anxiety, Social Concerns/Stress, Test Anxiety, and Worry/Oversensitivity) factors and one Lie factor along with a higher-order anxiety (i.e., a Total Anxiety) factor. However, to the author's knowledge, no measurement invariance study has been conducted with the AMAS-C with college students from different countries, such as Canada and the United States. Measurement invariance needs to be established before a measure developed in one country can be used in another country, even when countries appear to be culturally similar, as the interpretation of test scores in groups of individuals in the country where the measure was not developed (e.g., Canada, in the current study) and educational and psychological outcomes could be negatively impacted (Reynolds \& Lowe, 2009).

\subsection{Measurement Invariance, Cultural and Gender Differences, and Measures of Anxiety}

Measurement invariance is a sophisticated procedure that involves conducting a series of tests (Carle, Millsap, \& Cole, 2008) to determine whether the test scores of individuals in different groups being compared, such as Canadian and U.S. college students, are on the same measurement scale (Reise, Widaman, \& Pugh, 1993). Scores need to be on the same measurement scale in order to make comparisons between groups of interests. To determine measurement invariance, multi-group confirmatory factor analyses are conducted in which a series of nested models are tested and the models become more restricted as the testing process continues (Byrne, 2012). In this testing process, different sets of parameters (e.g., factor loadings, intercepts or thresholds) are sequentially constrained, making the models more restricted. The parameters are evaluated at each step along the way to determine whether they are equivalent across the groups of interest (Brown, 2006). If the parameters are found to be equivalent across groups of interest via invariance (i.e., configural, weak, and strong invariance) tests conducted, then the construct of interest, such as anxiety, is relatively the same across groups and group comparisons can be made (Byrne, 2012; Byrne, Shavelson, \& Muthén, 1989). The first step is to test for configural invariance. Configural invariance is when the factor structure or form of the measure is similar across groups (e.g., countries). The second test involves examining weak invariance. Weak invariance is when the corresponding factor loadings of a measure are similar across groups. The third step is to test for strong invariance. Strong invariance is when the corresponding factor loadings and intercepts (or thresholds) of a measure are similar (Brown, 2006; Little, 2013). Strong invariance is needed in order to make the same test score interpretation across groups (Byrne, 2012; Byrne et al., 1989). Invariance is important to establish when interpreting test scores (Byrne et al., 1989), as those with the same amount of a latent variable or characteristic, such as anxiety, should have similar observed test scores, suggesting no test bias exists in the measure (Meredith, 1993). Measurement invariance makes it possible for "researchers and clinicians to generalize results from validity studies to clinical practice" (Bowden, Saklofske, \& Weiss, 2011, p. 187).

A dearth of studies have examined invariance and similarities and differences in anxiety among Canadian and 
U.S. college students. Endler, Lobel, Parker, and Schmitz (1991) conducted a study with 1,296 American, Canadian, Israeli, and West German college students and found no differences between Canadian and U.S. males and females on the Trait scale of the EMAS (Endler et al., 1990). However, Endler et al. (1991) used the results of principal component analysis and congruence coefficients to examine whether the factor structure and loadings of the Trait scale of the EMAS were the same across nations and gender, followed by an examination of the differences in college students' observed scores. The authors found the factor structure and loadings were similar across Canadian and U.S. college students and reported no country differences among males and females. However, strong invariance and differences in the latent factor means were not explored in their study. Byrne et al. (1989) have stated that strong invariance needs to be determined in order for group comparisons to be made on a measure and that observed scores contain measurement error. Therefore, a study that examines the results of tests of measurement invariance and latent mean analyses across Canadian and U.S. college students on a measure of anxiety designed specifically for the U.S. college student population would be important to conduct in an area that has been understudied.

Gender differences have been explored on self-report measures of anxiety. Research has found females consistently reported higher levels of anxiety than males on self-reports in the college student population (Lowe \& Reynolds, 2005; McLean \& Hope, 2010; Twenge, 2000). Twenge conducted a meta-analysis with college students and reported a gender difference of .25 standard deviations, with females reporting higher levels of anxiety than males.

The purpose of the present study was to determine whether the construct of anxiety is similar across country (Canada, United States) and gender (male, female) among college students on a self-report measure of anxiety, the AMAS-C, which was designed specifically for the college-age student population. College students are reported to experience some anxieties that are unique to their age group (Pedrelli et al., 2015; Tosevski et al., 2010). Therefore, a measure, such as the AMAS-C, that addresses specific anxieties that college students experience would be beneficial for mental health professionals to use not only with U.S. college students, but also Canadian college students to identify those students with moderate to high levels of anxiety, so appropriate interventions can be implemented to reduce their anxiety symptoms. Because the AMAS-C was developed in the United States, a measurement invariance study is needed to determine whether the construct of anxiety, as measured by the AMAS-C, is similar across Canadian and U.S. college students, so the same test score interpretation can be used. Therefore, tests of configural, weak, and strong invariance were conducted across nations and gender in the present study. In addition, country and gender differences were explored by latent mean analyses. The research questions posed were:

1. Is the construct of anxiety, as measured by the AMAS-C, equivalent across gender and country?

2. Do country and gender differences exist between Canadian and U.S. undergraduate students on the AMAS-C?

\section{Method}

\subsection{Participants}

Participants included 1,344 (624 Canadian and 720 American) undergraduate students. There were 545 males and 799 females in the sample. The mean age of the college students was 21.36 ( $S D=2.37)$. The age breakdown of the undergraduate student sample by country and gender is presented in Table 1.

Examination of Table 1 indicates a larger percentage of U.S. females who are 19 years of age compared to Canadian females and a larger percentage of Canadian females who are 23 years of age compared to U.S. females, and a larger percentage of Canadian males who are 22 years of age compared to U.S. males and a larger percentage of U.S. males who are 25 years of age compared to Canadian males. The ethnic distribution of the Canadian students was Aboriginal (2.6\%), Asian (16.7\%), Black (5.4\%), Caucasian (67.3\%), Latino (1.0\%), and other (7.0\%) and the ethnic make-up of the U.S. students was Asian (9.3\%), Black/African American (13.8\%), Caucasian (51.1\%), Hispanic/Latino (17.1\%), Native American (1.0\%), and other (7.7\%). All provinces of Canada and all major geographic regions of the United States were represented where the students resided. All students were fluent in English.

\subsection{Instrument}

The AMAS-C was used in the present study. The AMAS-C is a self-report measure and includes 49 items. The AMAS-C consists of four anxiety (Physiological Anxiety, Social Concerns/Stress, Test Anxiety, and Worry/Oversensitivity) subscales, a Total Anxiety scale, and a Lie scale. The Physiological Anxiety subscale (8 items) measures the physical symptoms of anxiety and the Social Concerns/Stress subscale (7 items) assesses concerns a student has about the views of others. The Test Anxiety subscale (15 items) assesses anxiety 
experienced in evaluative situations and the Worry/Oversensitivity subscale (12 items) measures nervousness and worrisome thoughts. The Total Anxiety scale (42 items) measures overall manifest anxiety. The Lie scale (7 items) is a validity index used "to detect response bias based on social desirability" (Reynolds et al., 2003b, p. 9). Students respond to the AMAS-C items using a yes/no format (Reynolds et al., 2003b). Reynolds et al. reported coefficient alphas for the AMAS-C Total Anxiety scale scores, four anxiety subscale scores, and Lie scale scores of .72 to .95 for the U.S. norming sample. Evidence supporting the validity of inferences from the AMAS-C scores has been found (Lowe, 2013; Reynolds et al., 2003b).

Table 1. Age Breakdown by Country and Gender on the Adult Manifest Anxiety Scale-College Version (AMAS-C)

\begin{tabular}{lllllll}
\hline \multicolumn{2}{c}{ Canada } & \multicolumn{5}{l}{ United States } \\
\hline Age & Male & Female & Total & Male & Female & Total \\
\hline 18 & $20(7.6 \%)$ & $45(12.5 \%)$ & $65(10.4 \%)$ & $30(10.7 \%)$ & $70(15.9 \%)$ & $100(13.9 \%)$ \\
19 & $28(10.6 \%)$ & $43(11.9 \%)$ & $71(11.4 \%)$ & $33(11.7 \%)$ & $83(18.9 \%)$ & $116(16.1 \%)$ \\
20 & $36(13.6 \%)$ & $54(15.0 \%)$ & $90(14.4 \%)$ & $39(13.9 \%)$ & $80(18.2 \%)$ & $115(16.0 \%)$ \\
21 & $43(16.3 \%)$ & $47(13.1 \%)$ & $90(14.4 \%)$ & $47(16.7 \%)$ & $56(12.8 \%)$ & $103(14.3 \%)$ \\
22 & $47(17.8 \%)$ & $40(11.1 \%)$ & $87(13.9 \%)$ & $36(12.8 \%)$ & $55(12.5 \%)$ & $91(12.6 \%)$ \\
23 & $25(9.5 \%)$ & $43(11.9 \%)$ & $68(10.9 \%)$ & $25(8.9 \%)$ & $23(5.2 \%)$ & $48(6.7 \%)$ \\
24 & $30(11.4 \%)$ & $36(10.0 \%)$ & $66(10.6 \%)$ & $21(7.5 \%)$ & $22(5.0 \%)$ & $43(6.0 \%)$ \\
25 & $23(9.8 \%)$ & $24(6.7 \%)$ & $47(7.5 \%)$ & $41(14.6 \%)$ & $25(5.7 \%)$ & $67(9.3 \%)$ \\
26 & $12(4.5 \%)$ & $28(7.8 \%)$ & $40(6.4 \%)$ & $9(3.2 \%)$ & $25(5.7 \%)$ & $34(4.7 \%)$ \\
Total & $264(100 \%)$ & $360(100 \%)$ & $624(100 \%)$ & $281(100 \%)$ & $439(100 \%)$ & $720(100 \%)$ \\
\hline
\end{tabular}

\subsection{Procedures}

Students were recruited via Qualtrics, a U.S. web-based survey company. Each student was part of a Qualtrics panel. Individuals who are part of a Qualtrics panel volunteer to participate in on-line research-based studies. In the present study, the participants were informed that the author wished to develop and validate a test anxiety measure for college students to develop a better understanding of anxiety (i.e., test and manifest anxiety) in the college student population. The subjects were also informed that their participation in the study would not benefit them directly. Once the students gave their consent for the current study, they completed demographic information requested (e.g., their age, gender, name and location of college/university, state or province where they resided, and self-reported grade point average). Then they completed two measures, one of which was the AMAS-C and the other one was a test anxiety measure. Students received a small amount of money for their participation in the study. Institutional review board approval was granted at the author's university to conduct the study.

\section{Results}

Single-group CFAs were conducted for each of the eight different groups (i.e., Canadian males, Canadian females, U.S. males, U.S. females, males, females, Canadian students, and U.S. students). Mplus 7.11 (L. K. Muthén \& B. O. Muthén, 1998-2013) statistical software was used. In addition, the robust weighted least squares (WLSMV) estimator served as the parameter estimator for these analyses due to the binary nature of the responses to the indicators (i.e., items). To indicate acceptable model fit for the data for each of the eight different groups, Little's (2013) suggested guidelines were used-a RMSEA value of $\leq .08$ and a comparative fit index (CFI) value and a Tucker-Lewis index (TLI) value of $>.90$. Results of the single-group CFAs indicated an acceptable model fit to the data for the eight different groups (see Table 2).

Coefficient alphas were computed for the Total Anxiety scores, four AMAS-C anxiety subscale scores, and Lie scores across gender, country, and gender by country (see Table 3). The internal consistency reliability estimates ranged from .70 to .94 . Using Nunnally and Bernstein's (1994) criteria, these reliability estimates are considered to be in the adequate range. 
Table 2. Summary of the Fit Indices for the Eight Single Group (Canadian Males, Canadian Females, U.S. Males, U.S. Females, Males, Females, Canada, and United States) Confirmatory Factor Analyses and Tests of Invariance Across Canadian Males and Females, U.S. Males and Females, Males and Females, and Canada and the United States

\begin{tabular}{|c|c|c|c|c|c|c|c|c|c|c|}
\hline Model & WLSMV $\chi^{2}$ & $\mathrm{df}$ & $\Delta$ WLSMV $\chi^{2}$ & $\Delta d f$ & $P$ & CFI & $\triangle C F I$ & TLI & $\triangle \mathrm{RMSEA}$ & RMSEA(90\%CI) \\
\hline Canadian Males & $1445.347 * * * *$ & 1117 & & & & .951 & & .948 & & $.033(.028-.038)$ \\
\hline Canadian Females & $1664.787 * * * *$ & 1117 & & & & .944 & . & .941 & & $.037(.033-.041)$ \\
\hline 1.Configural & $3113.940 * * * *$ & 2234 & 64.760 & & & .946 & & .943 & & $.036(.033-.038)$ \\
\hline 2.Weak & $3106.076 * * * *$ & 2278 & 64.760 & 44 & .02 & .949 & .003 & .948 & .002 & $.034(.031-.037)$ \\
\hline 3.Strong & $3174.931 * * * *$ & 2322 & 118.756 & 44 & $<.01$ & .948 & .001 & .947 & .000 & $.034(.031-.037)$ \\
\hline U.S. Males & $1935.910 * * * *$ & 1117 & & & & .923 & & .919 & & $.037(.032-.041)$ \\
\hline U.S. Females & $1664.787 * * * *$ & 1117 & & & & .944 & . & .941 & & $.040(.038-.044)$ \\
\hline 1.Configural & $3469.169 * * * *$ & 2234 & & & & .931 & & .928 & & $.039(.037-.042)$ \\
\hline 2.Weak & $3422.854 * * * *$ & 2278 & 65.338 & 44 & .02 & .936 & .005 & .934 & .002 & $.037(.035-.040)$ \\
\hline 3.Strong & $3491.803 * * * *$ & 2322 & 116.938 & 44 & $<.01$ & .935 & .001 & .934 & .000 & $.037(.035-.040)$ \\
\hline Males & $2047.493 * * * *$ & 1117 & & & & .937 & & .933 & & $.039(.036-.042)$ \\
\hline Females & $2792.937 * * * *$ & 1117 & & & & .923 & . & .919 & & $.043(.041-.045)$ \\
\hline 1.Configural & $4842.455^{* * * * *}$ & 2234 & & & & .928 & & .924 & & $.042(.040-.043)$ \\
\hline 2.Weak & $4571.157 * * * *$ & 2278 & 56.151 & 44 & .10 & .937 & .009 & .935 & .003 & $.039(.037-.040)$ \\
\hline 3.Strong & $4675.522 * * * *$ & 2322 & 181.930 & 44 & $<.01$ & .935 & .002 & .934 & .000 & $.039(.037-.040)$ \\
\hline Canada & $2206.406^{* * * * *}$ & 1117 & & & & .945 & & .942 & & $.040(.037-.042)$ \\
\hline United States & $2580.855 * * * *$ & 1117 & & & & .929 & . & .925 & & $.040(.037-.042)$ \\
\hline 1.Configural & $4775.117 * * * *$ & 2234 & & & & .937 & & .934 & & $.041(.040-.043)$ \\
\hline 2.Weak & $4491.007 * * * *$ & 2278 & 53.699 & 44 & .15 & .945 & .008 & .944 & .003 & $.038(.036-.040)$ \\
\hline 3.Strong & $4557.193 * * * *$ & 2322 & 93.150 & 44 & $<.01$ & .945 & .000 & .944 & .000 & $.038(.036-.040)$ \\
\hline
\end{tabular}

WLSMV $\chi^{2}=$ robust mean-and variance-adjusted chi square, $\mathrm{df}=$ degrees of freedom, $\Delta$ WLSMV $\chi^{2}=$ change in the robust mean-and variance-adjusted chi square, $\Delta \mathrm{df}=$ change in degrees of freedom, $\mathrm{CFI}=$ comparative fit index, $\Delta \mathrm{CFI}=$ change in the comparative fit index, TLI $=$ Tucker-Lewis index, $\triangle \mathrm{RMSEA}=$ change in the root mean square error of approximation; RMSEA = root mean square error of approximation; $\mathrm{CI}=$ confidence interval; $* * * * p<.0001$.

Table 3. Coefficient Alphas for the Adult Manifest Anxiety Scale-College Version (AMAS-C) Scores across Gender, across Country (Canada, United States) and across Gender and Country

\begin{tabular}{lllllllll}
\hline Scale/Subscale & \multicolumn{2}{l}{ Canadian } & \multicolumn{2}{l}{ United States } & Males & Females & Canada & United States \\
\hline & Males & Females & Males & Females & & & & \\
\hline Physiological Anxiety & .82 & .82 & .83 & .82 & .82 & .82 & .83 & .83 \\
Social Concerns/Stress & .70 & .74 & .72 & .73 & .71 & .74 & .73 & .73 \\
Test Anxiety & .86 & .88 & .88 & .86 & .87 & .87 & .88 & .88 \\
Worry/Oversensitivity & .82 & .81 & .84 & .80 & .83 & .80 & .84 & .84 \\
Total & .92 & .93 & .94 & .92 & .94 & .93 & .94 & .94 \\
Lie & .73 & .73 & .70 & .74 & .71 & .74 & .73 & .72 \\
\hline
\end{tabular}

Multi-group CFAs were performed across Canadian males and females, U.S. males and females, males and females, and country (Canada, United States) to test for measurement invariance. Three levels of invariance (configural, weak, and strong invariance) were tested. There was multiple criteria used to determine whether invariance was tenable between a less and a more restrictive multi-group model. The criteria included a RMSEA value of the alternative model falling within the $90 \%$ confidence interval of the null model (Ginevra et al., 2015), a change in the RMSEA, $\triangle$ RMSEA, $\geq .015$ and a change in the CFI, $\triangle$ CFI, of $\leq-.01$ (Chen, 2007). Configural, weak, and strong invariance were considered tenable across the groups when the majority of criteria were met. Results indicated that configural, weak, and strong invariance appeared tenable for the four different comparisons (see Table 2).

Latent mean factor analyses followed across the four groups because strong invariance seemed tenable across these groups (Byrne et al., 1989). Latent mean analyses were conducted instead of examining differences in 
observed scores because latent variables do not have measurement error, whereas observed variables do. Therefore, the differences found between groups on a latent variable represent true differences across the groups of interest. Results of the latent mean factor analyses indicated Canadian females, U.S. females, and females had higher levels of physiological anxiety $(\beta=.558, \mathrm{SE}=.088, p<.001, d=.56 ; \beta=.352, \mathrm{SE}=.083, \mathrm{p}<.001, d=.35$; $\beta=.448, \mathrm{SE}=.060, \mathrm{p}<.001, d=.45)$, social concerns/stress $(\beta=.386, \mathrm{SE}=.084, \mathrm{p}<.001, d=.39 ; \beta=.319, \mathrm{SE}=.076$, $\mathrm{p}<.001 d=.32 ; \beta=.350, \mathrm{SE}=.057, \mathrm{p}<.001, d=.35)$, test anxiety $(\beta=.522, \mathrm{SE}=.081, \mathrm{p}<.001, d=.52 ; \beta=.547$, $\mathrm{SE}=.084, \mathrm{p}<.001, d=, 55 ; \beta=.537, \mathrm{SE}=.058, \mathrm{p}<.001, d=.54)$, and worry/oversensitivity $(\beta=.908, \mathrm{SE}=.092$, $\mathrm{p}<.001, d=.91 ; \beta=.738, \mathrm{SE}=.086, \mathrm{p}<.001, d=.74 ; \beta=.816, \mathrm{SE}=.063, \mathrm{p}<.001, d=.82)$ than Canadian males, U.S. males, and males, respectively. In these analyses, the effect sizes for the gender differences across the four anxiety variables ranged from small to large based on Cohen's (1988) criteria. These findings indicate that there are true gender differences between males and females in both countries and across countries, with females experiencing higher levels of physiological anxiety, social concerns/stress, test anxiety, and worry/oversensitivity than males. These findings also indicate that there are no true country differences in physiological anxiety, social concerns/stress, test anxiety, and worry/oversensitivity between Canadian and U.S. undergraduate students and that researchers and mental health professionals can use the same test score interpretation across male and female undergraduate students from these two countries. Furthermore, U.S. undergraduates were found to be higher on the lie variable $(\beta=.130, \mathrm{SE}=.064, \mathrm{p}=.042, d=.13)$ compared to Canadian undergraduates. However, the effect size was negligible, suggesting the significant difference reported on the lie variable is trivial.

\section{Discussion and Conclusion}

Overall, the findings indicated the AMAS-C was invariant across gender and country. These results suggest the AMAS-C scores can be interpreted the same for males and females and Canadian and U.S. undergraduate students. In addition, the results of latent mean analyses revealed that Canadian females, U.S. females, and females reported higher levels of physiological anxiety, social concerns/stress, test anxiety, and worry/oversensitivity than Canadian males, U.S. males, and males, respectively, with small to large effect sizes. These findings are similar to Lowe and Reynolds' (2005) and Reynolds et al.'s (2003b) studies with samples of U.S. college students, with females reporting higher levels of anxiety on all AMAS-C anxiety subscales, with the exception of no gender difference found on the Social Concerns/Stress subscale. The difference in findings may be due to the comparison of latent factor means in the present study versus the comparison of observed scores, which include measurement error, in Lowe and Reynolds' (2005) and Reynolds et al.'s (2003b) studies. The current findings also align with Reynolds' (1998) study where females reported higher levels of anxiety than males. In this study, Reynolds found that gender differences in anxiety began around age 6 and continued throughout the child and adult lifespan on different self-report measures of anxiety.

The results of latent mean analyses across country found no differences between Canadian and U.S. undergraduate students on the AMAS-C four anxiety subscales. These findings are similar to Endler et al.'s (1991) results of no country differences between Canadian and U.S. males and females on the Trait scale of the EMAS. In Endler et al.'s study, the authors compared observed scores, which contain measurement error, among the different groups on the Trait scale of the EMAS, whereas in the present study latent factor means, which contain no measurement error, were compared on the AMAS-C. The findings from these two studies provide support for no country differences on measures of trait anxiety among Canadian and U.S. college students. Moreover, these findings provide evidence to support the use of the AMAS-C with Canadian college students although additional studies need to be conducted.

The findings of the present study have important implications for mental health professionals, current and future researchers, and educational practitioners or faculty who work with college students. First, it is critically important for mental health professionals and current and future researchers who wish to examine cultural differences across nations on psychological constructs of interest to test the models and measures developed in the United States, for example, in other countries to determine whether those models and measures are similar across nations of interest prior to examining group differences. Mental health professionals and current and future researchers cannot assume that these models and measures developed in one country will automatically generalize to another country. Making such an assumption may result in ignoring the unique characteristics found among people of a specific country or particular culture (Smith, Saklofske, Yan, \& Sherry, 2015). Second, for Canadian and U.S. mental health professionals the same test score interpretation can be made on the AMAS-C when comparing male and female English-speaking undergraduates from Canada and the United States. In addition, separate gender norms are not needed for Canadian and U.S. college students on the AMAS-C. Third, the AMAS-C validity index (i.e., Lie scale) operates the same for Canadian and U.S. male and female college students. Therefore, an elevated score on this scale is most likely to indicate that a protocol is not 
valid and should not be used in the interpretation of measures included in a psychological report. Fourth, the differences in anxiety reported between males and females in Canada and the United States represent true differences. Therefore, mental health professionals need to be cognizant that females are at a higher risk than males to report clinically significant levels of anxiety and intervention as well as prevention efforts should be targeted to specifically reduce or prevent anxiety symptoms in the female undergraduate student population in both countries. Fifth, although additional research is needed, high scores on particular subscales of the AMAS-C may help mental health professionals determine how best to intervene with Canadian and U.S. college students who experience anxiety. Relaxation training and biofeedback have been shown to reduce the physiological symptoms of anxiety. Problem solving skills are often helpful in decreasing social concerns, and cognitive-behavioral techniques, such as cognitive-behavior therapy or rational emotive behavioral therapy, are often beneficial in reducing worrisome thoughts and test anxiety (see Ergene, 2003; Henderson \& Thompson, 2016; Huberty, 2008; Zeidner, 1998). Finally, for educational practitioners or faculty who work with anxious college students, research has shown creating a positive, non-competitive classroom environment has been found to be helpful in reducing some students' anxious feelings (Posselt \& Lipson, 2016). Because females were found to be at a higher risk for anxiety in the current study, it may be beneficial for educational practitioners or faculty to assess their classroom environments and make adjustments where needed to lower the levels of anxiety students may experience in their classrooms.

There are several limitations associated with the present study. First, more females than males participated in the current study. Although female college students tend to participate more than males in studies at the college level, future studies should try to include percentages of male and female college students reflective of the Canadian and U.S. student populations. A second limitation is that there was a larger percentage of U.S. and Canadian females who were 19 and 23 years of age, respectively, and a larger percentage of Canadian and U.S. males who were 22 and 25 years of age, respectively. Again, future studies should try to include percentages of college students of certain ages reflective of the Canadian and U.S. student populations. Other limitations associated with the present study involved the diversity of the sample. There was a larger percentage of Asians in both the Canadian and U.S. undergraduate samples and a lower percentage of Aborigines in the Canadian undergraduate sample in comparison to their respective populations (Statistics Canada, 2011; U.S. Bureau of the Census, 2010, 2011a, 2011b). Future studies should include more representative samples that mirror the Canadian and U.S. college student populations. Other future research directions with the AMAS-C include temporal stability studies and additional convergent and discriminant validity studies with Canadian undergraduate students as well as measurement invariance studies with French-speaking Canadian and U.S. undergraduate students. Overall, the findings from the present study suggest that the AMAS-C appears to be a promising and useful measure for practicing mental health professionals and researchers to use in the area of anxiety among North American undergraduate student populations.

\section{References}

American Psychological Association. (2015). Stress in America: Paying with our health. Washington, DC: American Psychological Association.

Bassani, C. D. (2005). A cross-national examination of the effect of family and school social capital on youths' mathematics scores in Canada, Japan, and the United States (Doctoral dissertation). Retrieved from ProQuest Dissertation \& Theses: Full Text (NR06945).

Bodas, J., \& Ollendick, T. H. (2005). Test anxiety: A cross-cultural perspective. Clinical Child and Family Psychology Review, 8, 65-88. https://doi.org/10.1007/s10567-005-2342-x

Bowden, S. C., Saklofske, D. H., \& Weiss, L. G. (2011). Invariance of the measurement model underlying the Wechsler Adult Intelligence Scale-IV in the United States and Canada. Educational and Psychological Measurement, 71, 186-189. https://doi.org/10.1177/0013164410387382

Bowman, M. L. (2000). The diversity of diversity: Canadian-American differences and their implications for clinical training and APA accreditation. Canadian Psychology, 41, 230-243. https://doi.org/10.1037/h0086871

Brown, T. A. (2006). Confirmatory factor analysis for applied research. New York: Guilford Press.

Byrne, B. M. (2012). Structural equation modeling with Mplus: Basic concepts, applications, and programming. New York, NY: Routledge.

Byrne, B. M., Shavelson, R. J., \& Muthén, B. (1989). Testing for the equivalence of factor covariance and mean structures: The issue of partial measurement invariance. Psychological Bulletin, 105, 456-466. 
https://doi.org/10.1037/0033-2909.105.3.456

Carle, A. C., Millsap, R. E., \& Cole, D. A. (2008). Measurement bias across gender on the Children's Depression Inventory: Evidence for invariance from two latent variable models. Educational and Psychological Measurement, 68, 281-303. https://doi.org/10.1177/0013164407308471

Chen, F. F. (2007). Sensitivity of goodness of fit indexes to lack of measurement invariance. Structural Equation Modeling, 14, 464-504. https://doi.org/10.1080/10705510701301834

Cohen, J. (1988). Statistical power analysis for the behavioral sciences. Hillsdale, NJ: Lawrence Erlbaum Associates.

Craggs, S. (2012). One-third of McMaster students battle depression: Survey. CBC news. Retrieved from http://www.cbc.ca/Hamilton/news/story/2012/10/02/Hamilton-mental-illness-awareness-week.html

Cranford, J. A., Eisenberg, D., \& Serras, A. M. (2009). Substance use behaviors, mental health problems, and use of mental health services in a probability sample of college students. Addictive Behaviors, 34, 134-145. https://doi.org/10.1016/j.addbeh.2008.09.004

DeCarlo, Santiago, C., Wadsworth, M. E., \& Stump, J. (2011). Socioeconomic status, neighborhood disadvantage and poverty related stress: Prospective effects on psychological syndromes among diverse low-income families. Journal of Economic Policy, 32(2), 218-230. https://doi.org/10.1016/j.joep.2009.10.008

Eisenberg, D., Gollust, S. E., Golberstein, E., \& Hefner, J. L. (2007). Prevalence and correlates of depression, anxiety, and suicidality among university students. American Journal of Orthopsychiatry, 77, 534-542. https://doi.org/10.1037/0002-9432.77.4.534

Endler, N. S., Edwards, J. M., \& Vitelli, R. (1990). Endler Multidimensional Anxiety Scales (EMAS). Los Angeles, CA: Western Psychological Services.

Endler, N. S., Lobel, T., Parker, J. D. A., \& Schmitz, P. (1991). Multidimensionality of state and trait anxiety: A cross-cultural study comparing American, Canadian, Israeli, and German young adults. Anxiety Research, 3, 257-272. https://doi.org/10.1080/08917779108248756

Ergene, T. (2003). Effective interventions on test anxiety reduction: A meta-analysis. School Psychology International, 24, 313-328. https://doi.org/10.1177/01430343030243004

Gerwing, T. G., Rash, J. A., Gerwing, A. M. A., Bramble, B., \& Landine, J. (2015). Perceptions and incidence of test anxiety. The Canadian Journal of Scholarship of Teaching and Learning, 6(3), 1-14. https://doi.org/10.5206/cjsotl-rcacea.2015.3.3

Ginevra, M. C., Nota, L., Soresi, S., Shogren, K. A., Wehmeyer, M. L., \& Little, T. D. (2015). A cross-cultural comparison of the self-determination construct in Italian and American adolescents. International Journal of Adolescence and Youth, 20, 501-517. https://doi.org/10.1080/02673843.2013.808159.

Henderson, D. A., \& Thompson, C. L. (2016). Counseling children ( $\left(^{\text {th }}\right.$ ed.). Boston, MA: Cengage Learning.

Huberty, T. J. (2008). Best practices in school-based interventions for anxiety and depression. In A. Thomas \& J. Grimes (Eds.), Best practices in school psychology V. Bethesda, MD: The National Association of School Psychologists.

Kessler, R. C., Frank, R. G., Edlund, M., Katz, S. J., Lin, E. \& Leaf, P. (1997). Differences in the use of psychiatric outpatient services between the United States and Ontario. New England Journal of Medicine, 336(8), 551-557. https://doi.org/10.1056/NEJM199702203360806

Lowe, P. A. (2013). Validation of the Adult Manifest Anxiety Scale-College version scores among U.S. college students. Canadian Journal of School Psychology, 28, 277-294. https://doi.org/10.1177/0829573513497907

Lowe, P. A., \& Reynolds, C. R. (2005). Factor structure of the AMAS-C scores across gender among students in collegiate settings. Educational and Psychological Measurement, 65, 687-708. https://doi.org/10.1177/0013164405275659

Little, T. D. (2013). Longitudinal structural equation modeling. New York, NY: Guilford Press.

McLean, C. P., \& Hope, D. A. (2010). Subjective anxiety and behavioral avoidance: Gender, gender role, and perceived confirmability of self-report. Journal of Anxiety Disorders, 24, 494-502.

https://doi.org/10.1037/t11593-000

Meredith, W. (1993). Measurement invariance, factor analysis, and factorial invariance. Psychometrika, 58, 
525-543. https://doi.org/10.1007/BF02294825

Muthén, L. K., \& Muthén, B. O. (1998-2013). Mplus Version 7.11. Los Angeles, CA: Muthén \& Muthén.

Nunes, M., Walker, J. R., Syed, T., Jong, M. D., Stewart, D. W., Provencher, M. D., ... the Mobilizing Minds Research Group (2014). A national survey of student extended health insurance programs in postsecondary institutions in Canada: Limited support for students with mental health problems. Canadian Psychology, 55, 101-109. https://doi.org/10.1037/a0036476

Nunnally, J. C., \& Bernstein, I. H. (1994). Psychometric theory (3rd ed.). New York, NY: McGraw-Hill.

Pedrelli, P., Nyer, M., Yeung, A., Zulauf, C., \& Wilens, T. (2015). College students: Mental health problems and treatment considerations. Academic Psychiatry, 39, 503-511. https://doi.org/10.1007/s40596-014-0205-9

Posselt, J. R., \& Lipson, S. K. (2016). Competition, anxiety, and depression in the college classroom: Variations by student identity and field of study. Journal of College Student Development, 57, 973-989. https://doi.org/10.1353/csd.2016.0094

Regehr, C., Glancy, D., \& Pitts, A. (2013). Interventions to reduce stress in university students: A Review and meta-analysis. Journal of Affective Disorders, 148, 1-11. https://doi.org/10.1016/j.jad.2012.11.02

Reise, S. P., Widaman, K. F., \& Pugh, R. H. (1993). Confirmatory factor analysis and item response theory: Two approaches for exploring measurement invariance. Psychological Bulletin, 114, 552-566. https://doi.org/10.1037/0033-2909.114.3.552

Reynolds, C. R. (1985). Multitrait validation of the Revised Children's Manifest Anxiety Scale for children of high intelligence. Psychological Reports, 56, 402. https://doi.org/10.2466/pr0.1985.56.2.402

Reynolds, C. R. (1998). Need we measure anxiety differently for males and females? Journal of Personality Assessment, 70, 212-221. https://doi.org/10.1207/s15327752jpa7002_2

Reynolds, C. R., \& Lowe, P. A. (2009). The problem of bias in psychological assessment. In T. B. Gutkin \& C. R. Reynolds (Eds.), The handbook of school psychology (4th ed., pp. 332-374). New York: John Wiley.

Reynolds, C. R., Richmond, B. O., \& Lowe, P. A. (2003a). The Adult Manifest Anxiety Scale-College Version. Los Angeles: Western Psychological Services.

Reynolds, C. R., Richmond, B. O., \& Lowe, P. A. (2003b). The Adult Manifest Anxiety Scale-College Version manual. Los Angeles: Western Psychological Services.

Spence, J. T., \& Spence, K. W. (1966). The motivational components of manifest anxiety: Drive and drive stimuli. In C. D. Spielberger (Ed.), Anxiety and behavior (pp. 291-326). New York: Academic Press.

Spielberger, C. D., Gorsuch, R. L., \& Lushene, R. (1977). State-Trait Anxiety Inventory for Adults. Palo Alto, CA: Consulting Psychologists Press.

Smith, M. M., Saklofske, D. H., Yan, G., \& Sherry, S. B. (2016). Cultural similarities in perfectionism: Perfectionistic strivings and concerns generalize across Chinese and Canadian groups. Measurement and Evaluation in Counseling and Development, 49, 63-76. https://doi.org/10.1177/0748175615596785

Statistics Canada. (2011). Statistics Canada, 2011 National Household Survey. Retrieved from http://www.statcan.gc.ca

Stallman, H. M. (2010). Psychological distress in university students: A comparison with general population data. Australian Psychologist, 45, 249-257. https://doi.org/10.1080/00050067.2010.482109

Stelnicki, A. M., Nordstokke, D. W., \& Saklofske, D. H. (2015). Who is he successful university student? An analysis of personal resources. Canadian Journal of Higher Education, 45(2), 214-228.

Tosevski, D. L., Milvancevic, M. P., \& Gajic, S. D. (2010). Personality and psychopathology of university students. Current Opinion in Psychiatry, 23, 48-52. https://doi.org/10.1097/YCO.0b013e328333d625

Triventi, M. (2014). Higher education regimes: An empirical classification of higher education systems and its relationship with student accessibility. Quality and Quantity: International Journal of Methodology, 48, 1685-1703. https://doi.org/10.1007/s11135-013-9868-7

Twenge, J. M. (2000). The age of anxiety? The birth cohort change in anxiety and neuroticism, 1952-1993. Journal of Personality and Social Psychology, 79, 1007-1021. https://doi.org/10.1037/0022-3514.79.6.1007

U.S. Bureau of the Census. (2010). The White population: 2010 (Census brief, August 2010, Document No. C2010BR-05). Washington, DC: U.S. Bureau of the Census. 
U.S. Bureau of the Census. (2011a). The Black population: 2010 (Census brief, September 2011, Document No. C2010BR-06). Washington, DC: U.S. Bureau of the Census.

U.S. Bureau of the Census. (2011b). The Hispanic population: 2010 (Census brief, May 2011, Document No. C2010BR-04). Washington, DC: U.S. Bureau of the Census.

Zeidner, M. (1998). Test anxiety: The state of the art. New York: Plenum Press.

Zivin, K., Eisenberg, D., Gollust, S. E., \& Golberstein, E. (2009). Persistence of mental health problems and needs in a college student population. Journal of Affective Disorders, 117, 180-185.

https://doi.org/10.1016/j.jad.2009.01.001

\section{Copyrights}

Copyright for this article is retained by the author(s), with first publication rights granted to the journal.

This is an open-access article distributed under the terms and conditions of the Creative Commons Attribution license (http://creativecommons.org/licenses/by/4.0/). 